\title{
Inhibition of chondrogenic differentiation in chick limb-bud mesenchyme microcultures treated with cyclosporine
}

\author{
Soghra Bahmanpour, ${ }^{1}$ Douglas F. Paulsen²
}

${ }^{1}$ Anatomy Department, Shiraz University of Medical Sciences, Shiraz, Iran. ${ }^{2}$ Departments of Anatomy \& Neurobiology, Morehouse School of Medicine, Atlanta,

GA, USA.

Received: 14.5.2005

Revised: 6.10.2005 Accepted: 30.10 .2005

Correspondence to: Soghra Bahmanpour E-mail: bahmans@sums.ac.ir

\begin{abstract}
Objectives: To explore the effects of cyclosporine (CsA) on skeletal development (chondrogenesis).

Materials and Methods: Mesenchymal cells obtained from stage-23 to stage-24 chickembryo limb buds were grown in 96-well plates using chemically defined tissue-culture medium. Cultures were treated with $\mathrm{CsA}(0.01-5.0 \mu \mathrm{g} / \mathrm{ml})$ and incubated $\left(37^{\circ} \mathrm{C}, 5 \% \mathrm{CO}_{2}\right)$ with daily medium changes for 4 days. After incubation of the cells in multiwell plate, cartilage differentiation (chondrogenesis) was assessed by selectively staining sulfated glycosaminoglycans (GAGs) in the cartilage matrix with Alcian blue, extracting the GAGs with $4 M$ guanidinium $\mathrm{HCl}$, and spectrophotometric analysis of the extracts.

Results: CsA treatment had concentration-dependent effects on chick limb-bud mesenchymal cell cultures. At $5 \mu \mathrm{g} / \mathrm{ml}$, CsA caused cell loss, as judged microscopically by the paucity of cells remaining at the end of the culture period. CsA concentrations between 0.1 and $1 \mu \mathrm{g} / \mathrm{ml}$ caused a marked, dose-dependent decrease in chondrogenesis. At $0.01 \mu \mathrm{g} / \mathrm{ml}$, CsA had no significant effect on chondrogenesis. At concentrations above $0.01 \mu \mathrm{g} / \mathrm{ml}$, normalized data showed significant chondrogenic inhibition at 0.5 and $1.0 \mu \mathrm{g} / \mathrm{ml} \mathrm{CsA}$.

Conclusions: The findings suggest a possible biological basis for CsA-associated effects on mesenchyme-derived tissues and provide a model system for further studies.

KEY WORDS: Chondrogenesis, skeletal development spectrophotometric analysis
\end{abstract}

\section{Introduction}

Cyclosporine-A (CsA) therapy is a common and effective immunosuppressive treatment for transplant recipients and, increasingly, for autoimmune disorders. ${ }^{[1]}$ Recently, CsA has also been shown to reduce CD4+ T-cell loss in HIV-infected patients. ${ }^{[2]}$ CsA inhibits T-lymphocyte activation by inhibiting calcineurin activity, and thereby inhibiting cytokine production (e.g., interleukin-2 and interferon-ã). ${ }^{[3,4]}$ Calcineurin is a heterodimeric, calcium-dependent serine/threonine phosphatase, whose wide distribution in vertebrate tissues may account for CsA's effects on many nonlymphoid cell functions. ${ }^{[5,6]}$ Indeed, CsA is often used as a specific inhibitor in studies of calcineurin's regulatory effects in a variety of tissue types. ${ }^{[6-8]}$

CsA's increasing use in reproductive-age women and its apparent capacity for effects on a variety of tissues have raised concerns about its teratogenic potential. Reports of major malformations in live human births after CsA exposure during pregnancy are rare. Yet, understandable limitations on randomized, controlled studies in humans; the absence of comparisons of exposure during embryonic and fetal periods, confounding influences of other drug therapies that accompany CsA treatment (e.g., glucocorticoids). Variable CsA dosage and pharmacokinetic patterns, and trends toward increased risk of prematurity, low birth weight, and congenital malformation-all indicate a continuing need both for caution in prescribing CsA and monitoring during pregnancy and for further studies on the effects of CsA on embryonic and fetal tissues. ${ }^{[9]}$

Although there is evidence that placental transfer of CsA is limited in rabbits and rodents, ${ }^{[10]}$ its ability to reach human embryos and fetuses has been established. ${ }^{[11]}$ At least one case of CsA-induced osseous malformations, including limb defects, has been reported. ${ }^{[12]}$ When vertebrate embryos have been directly exposed to CsA, significant anomalies in the heart and other mesenchyme-derived tissues and organs have occurred. ${ }^{[6,8,11,13]}$ Adult skeletal and connective tissues exposed to CsA show alterations in extracellular matrix synthesis and secretion, ${ }^{[14,15]}$ suggesting a possible mechanism for altered development when calcineurin signaling is disrupted. Recently, calcineurin mRNA expression has been demonstrated in chick limb-bud mesenchyme. ${ }^{|8|}$ Thus, 
analyses of CsA effects on extracellular matrix synthesis and secretion in cultures of limb-bud mesenchyme may improve our understanding of CsA's capacity to disrupt normal development.

A further aim of this study was to adapt and validate a modified microtiter micromass culture model ${ }^{[16]}$ to explore CsA effects on in vitro cartilage differentiation (chondrogenesis). Micromass cultures of embryonic limbbud mesenchyme have been used and adapted to study many factors affecting differentiation. ${ }^{[17]}$ Mesenchymal cells isolated from embryonic limb buds undergo differentiation in tissue culture following a sequence of steps remarkably similar to those occurring in vivo. ${ }^{|17,18|}$ In part because of their accessibility, chick limb-bud mesenchymal cells have been especially useful in studies of differentiation mechanisms and in screening drugs and other compounds for toxicity and teratogenicity. ${ }^{[17-19]}$ Extracellular accumulation of cartilage proteoglycan aggregates (aggrecan) in these cultures serves as the primary endpoint for assessing chondrogenesis. ${ }^{[15-18]}$ Cartilage proteoglycans consist primarily of chondroitinsulfate glycosaminoglycan (GAG) side chains covalently linked to a core protein. Individual proteoglycans interact with hyaluronan to form large proteoglycan aggregates. Proteoglycans of noncartilage connective tissues form smaller aggregates and have a different composition with respect to types and relative amounts of GAGs and core proteins. ${ }^{[20]}$ The amount of aggrecan accumulated in the extracellular matrix can be assessed by staining the culture with Alcian blue at $\mathrm{pH} 1$, limiting its binding to sulfate groups in the matrix GAGs. ${ }^{[16]}$ Compounds that interfere with cartilage differentiation affect aggrecan accumulation, and thus the amount of Alcian-blue stain specifically bound by the cultures. Changes in Alcian-blue staining in CsA-treated cultures therefore reflect effects on cartilage differentiation from mesenchyme and may provide insight into CsA's potential for disrupting skeletogenesis.

\section{Materials and Methods}

\section{Tissue culture}

Cell suspensions were prepared from the wing buds of stage-23 to stage-24 chicken embryos, as described earlier. ${ }^{[21]}$ The embryos were collected in Tyrode's buffered salt solution (TBSS, Sigma, St. Louis, MO). The staging was confirmed under a dissecting microscope, the amniotic membranes removed, and the wing buds were excised from the body wall, taking care not to include any flank tissue.

The wing buds were collected using a Pasteur pipet, delivered to a $15 \mathrm{ml}$ centrifuge tube (Corning) containing 5 $\mathrm{ml}$ room temperature TBSS, and allowed to sediment at $1 \mathrm{~g}$. The supernatant was removed and discarded (further reducing blood cell contamination) and the limb-buds were resuspended in $2 \mathrm{ml}$ of trypsin-collagenase $(0.1 \%$ trypsin [GIBCO/BRL] and $0.1 \%$ collagenase [Worthington], with $2 \%$ heat-inactivated chicken serum in calcium- and magnesiumfree TBSS). The limb buds and enzyme solution were then delivered to a sterile $25 \mathrm{ml}$ Erlenmeyer flask and rotated at $70 \mathrm{rpm}$ in a $37^{\circ} \mathrm{C}$ water bath. After $3 \mathrm{~min}$, the limbs were triturated with a Pasteur pipette to obtain a single-cell suspension. Occasionally, the dissociation was visually judged incomplete and the flask and its contents were returned to the water bath for an additional 1-3 min. After a final trituration, the suspension was passed through a $20 \mu \mathrm{m}$ nylon mesh filter (Nitex) to remove any remaining cell aggregates and sheets of ectoderm; $5 \mathrm{ml}$ of unsupplemented F12/DMEM ( $50: 50$, Cellgro) were added to the suspension to dilute the enzyme. The resulting single-cell suspension was pelleted and resuspended in $5 \mathrm{ml}$ of complete defined medium (DM, F12/DMEM supplemented with $100 \mathrm{n} M$ hydrocortisone (Sigma), $5 \mu \mathrm{g} / \mathrm{l}$ insulin (Collaborative Research, MA), $5 \mu \mathrm{g} / \mathrm{ml}$ chicken transferrin (conalbumin, Sigma), $1 \mathrm{mg} / \mathrm{ml}$ L-ascorbic acid (Sigma), and the antibiotics penicillin, streptomycin, and fungizone (GIBCO) $)^{[16]}$ to further dilute the enzyme and facilitate cell counting. The cell density of the resulting suspension was determined using a hemacytometer. Trypanblue exclusion testing showed that this dissociation procedure yields suspensions with more than 95\% viability. After counting, the cells were pelleted and resuspended in an appropriate amount of DM to yield a density of $1 \times 10^{6}$ cells/ $\mathrm{ml}$. Aliquots $(250 \mu \mathrm{l})$ of this suspension $\left(2.5 \times 10^{5}\right.$ cells $)$ were inoculated into each well of a 96 -well, tissue-culture-treated, flat-bottomed, microtiter plate (Costar).

This plating procedure represents a departure from previous studies in which a $10 \mu \mathrm{l}$ droplet containing the same number of cells was delivered to each well. ${ }^{[16]}$ The modification was made for several reasons. It is difficult to center the droplet in these wells. If the droplet touches the wall, its surface tension is disrupted, resulting in a crescent of cells along the contacted wall. In addition, because there is no room in the small wells to add medium to counteract evaporation during the attachment period, there were concerns that evaporation from such small drops would increase the concentration of the many medium components during attachment, producing effects that might be inconsistent from well to well and difficult to assess. Delivering $250 \mu \mathrm{l}$ aliquots to each well results in a more homogeneous and reproducible cell distribution over the well surface. Obviously, the plating density is reduced by this modification. However, as the data reported demonstrate, this modified procedure results in measurable chondrogenesis and DNA content. Further, because it was unknown prior to this study of whether CsA would enhance or inhibit chondrogenesis in these cultures, or whether there would be an effect on cell proliferation, the lower density provides the added advantage of assessing changes in either direction. After seeding, the plates were incubated at $37^{\circ} \mathrm{C}$ in a water-jacketed incubator containing a humidified atmosphere of $5 \% \mathrm{CO}_{2}$ for a period of $2 \mathrm{~h}$ to allow initial attachment before adding the treatments. CsA treatment.

Because CsA may cause hepatotoxicity and nephrotoxicity in patients undergoing immunosuppressive therapy, monitoring of circulating CsA concentrations is often requested in order to maintain a therapeutic range. ${ }^{[5]}$ However, individual differences in pharmacokinetics ${ }^{[5]}$ and concerns about the accuracy of the methods used to monitor CsA concentration in the blood ${ }^{[7]}$ makes it difficult to pinpoint ideal therapeutic doses or circulating concentrations. Nevertheless, circulating CsA concentrations have been reported to range between 0.1 and $2.0 \mu \mathrm{g} / \mathrm{ml}$, although substantially higher 
concentrations have been detected in some individuals..$^{[5,22]}$ The CsA concentrations used for this study were chosen to bracket this range.

CsA was obtained as a purified powder (Sigma, St. Louis, Missouri). Fresh treatments were prepared for each experiment because preliminary studies showed a diminished effect in cultures treated with stocks older than 1 week (data not shown). A primary stock solution of $5 \mathrm{mg} / \mathrm{ml} \mathrm{CsA}$ in $100 \%$ ethanol (EtOH) was prepared. A secondary stock containing $50 \mu \mathrm{g} / \mathrm{ml} \mathrm{CsA}$ was then prepared by dilution in DM. Additional stocks were prepared by dilution in DM to create treatments containing the various CsA concentrations $(0.01,0.1,0.5,1$, and $5 \mu \mathrm{g} / \mathrm{ml})$. The vehicle control treatment was prepared containing EtOH equivalent to that in the $5 \mu \mathrm{g}$ $\mathrm{CsA} / \mathrm{ml}$ treatment $(0.1 \% \mathrm{EtOH}$ in DM). After the attachment period, $25 \mu \mathrm{l}$ of a $10 \mathrm{X}$ concentration of the appropriate treatment was delivered to the plating medium (DM) in each well. The cultures were grown for 4 days with careful daily complete replacement with $250 \mu \mathrm{l}$ of DM alone or containing the appropriate treatment, or vehicle control medium.

Chondrogenesis measurements

After collecting the DNA data, the cultures were rinsed twice with TBSS, fixed by the method of Carlson et al., ${ }^{1231}$ and washed twice with distilled water. Fixed cultures were stained overnight with $0.5 \%$ Alcian blue (ICN) in $0.1 \mathrm{~N} \mathrm{HCl}$ in deionized water and rinsed twice with $0.1 \mathrm{~N} \mathrm{HCl}$ to remove any unbound dye. ${ }^{[15]}$ The final rinse with distilled water was aspirated from each well to near dryness. Each well then received $100 \mu \mathrm{l}$ of $4 M$ guanidinium $\mathrm{HCl}(\mathrm{GuHCl}, \mathrm{pH} 5.8)$ to solubilize the stained matrix GAGs. The plate was sealed with parafilm $(3 M)$ and allowed to stand overnight at $4^{\circ} \mathrm{C}$. The plate was then allowed to warm to room temperature before obtaining absorbance values for each well using a Titertek microtiter plate reader (Molecular Devices) with a 600-nm filter. After obtaining the gross reading, the $\mathrm{GuHCl}$ was removed, the wells washed twice with deionized water, and $100 \mu \mathrm{l}$ of fresh $4 M \mathrm{GuHCl}$ was delivered to each well. The plate was read again to obtain blank values, which were then subtracted from the respective gross values to give the net absorbance of the extracted Alcianblue stain for each well.

\section{Statistical methods}

The data were subjected to one-way analysis of variance (ANOVA), followed by multiple comparison testing using Fisher's least significant difference. Post hoc Spearman rank correlation testing of the means confirmed concentration dependency. Significance was attributed at $P<0.05$.

\section{Results}

\section{Controls}

Because EtOH (1.0-1.5\%) has been shown to enhance matrix synthesis in similar cultures ${ }^{\mid 24]}$ reasonable concerns may be raised regarding contributions by the vehicle to these results. The microscopic appearance of the Alcian-bluestained cultures (Figure 1) and chondrogenesis [Figure 2(A)] are suggestive of EtOH-mediated enhancements for cultures grown in DM supplemented by the highest vehicle concentration used in these studies $(0.1 \% \mathrm{EtOH})$. However, the differences of the values obtained for chondrogenesis between the DM-only and vehicle controls were not statistically significant [Figure 2(A,B); $P>0.05$ ]. Thus, it seems

Figure 1. Cyclosporin (CsA) effects on culture morphology. Morphology of representative 4-day cultures of chick limb-bud mesenchyme grown in (A) defined medium (DM), (B) DM + 0.1\% ethanol (vehicle control), (C) $0.01 \mu \mathrm{g} \mathrm{CsA} / \mathrm{ml},(\mathrm{D}) 0.1 \mu \mathrm{g} \mathrm{CsA} / \mathrm{ml}$, (E) $0.5 \mu \mathrm{g} \mathrm{CsA} / \mathrm{ml}$, and (F) $1 \mu \mathrm{g} \mathrm{CsA} / \mathrm{ml}$. Cartilage nodules demonstrated by Alcian-blue staining at $\mathrm{pH} 1$. Note the decreasing cartilage-matrix accumulation with increasing CsA concentrations.

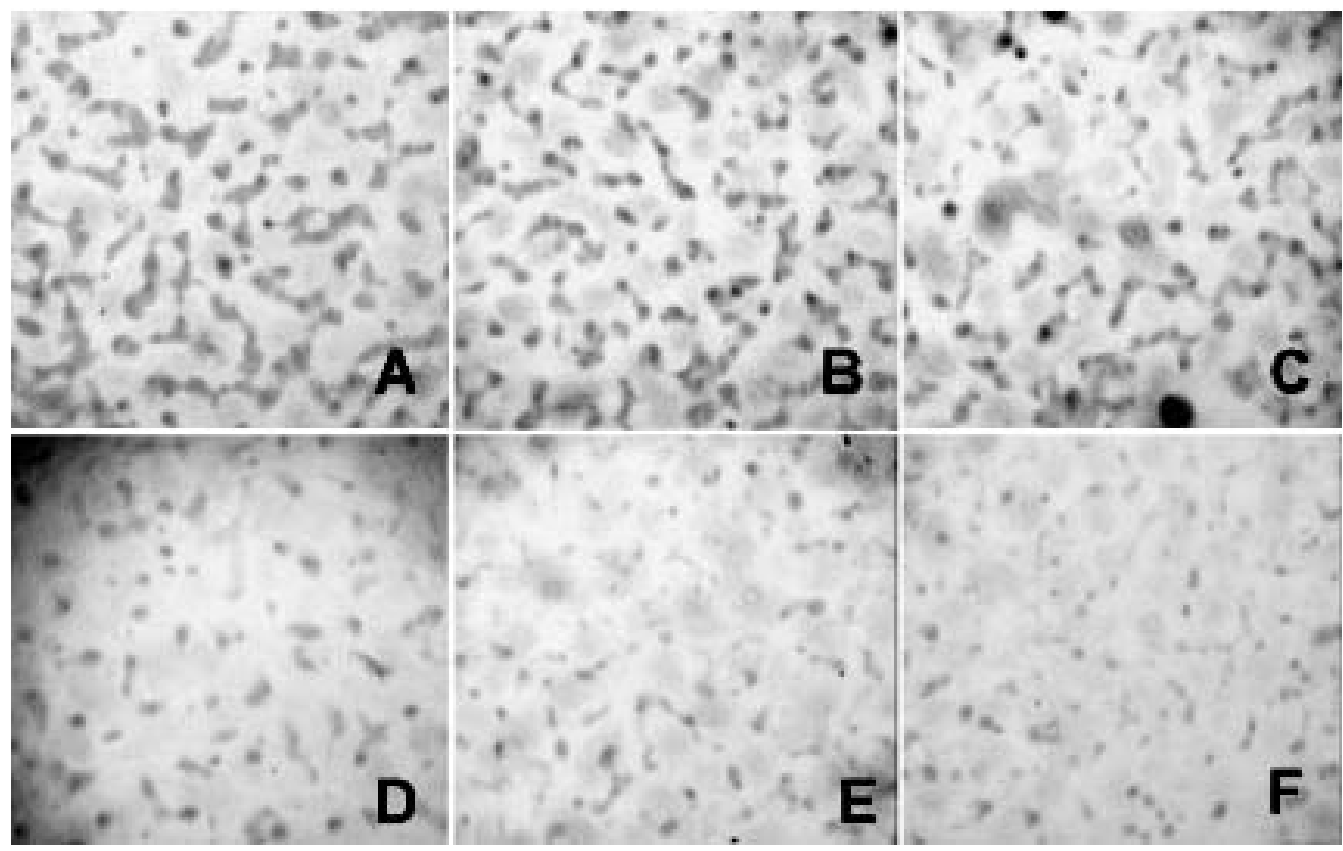


Figure 2. CsA effects on chondrogenesis: quantitative estimates of chondrogenesis in treated and untreated companion microcultures of stage 23-24 chick wing-bud mesenchymal cells grown for 4 days in presence of different CsA concentrations. (A) Chondrogenesis as determined by absorbance at $600 \mathrm{~nm}\left(\mathrm{~A}_{600}\right)$ per well in $100 \mu \mathrm{l}, 4 \mathrm{M}$ guanidinium $\mathrm{HCl}$ extracts. (B) Chondrogenesis values $\left(A_{600}\right)$ normalized, well-by-well, to DNA content $\left(A_{600} \times 100 /\right.$ $\mu \mathrm{g}$ DNA). $N=$ number of culture wells in each group. Variations in $N$ values for the data points in these graphs reflect occasional technical errors in the delivery of reagents to, or the disruption or loss of tissue from, some wells during processing. Normalized values (B) are reported only for wells from which reliable data for chondrogenesis were obtained. Values are mean \pm standard error. Significantly different from DM control: ${ }^{*} P<0.05,{ }^{*} P<0.01$, ${ }^{* * *} P<0.001$. Significantly different from vehicle $(0.1 \% \mathrm{EtOH})$ control: ${ }^{\dagger} P<0.05,{ }^{\dagger+} P<0.01,{ }^{\dagger+} P<0.001$. Significantly different from other treatment concentrations: ${ }^{\ddagger} P<0.001$.
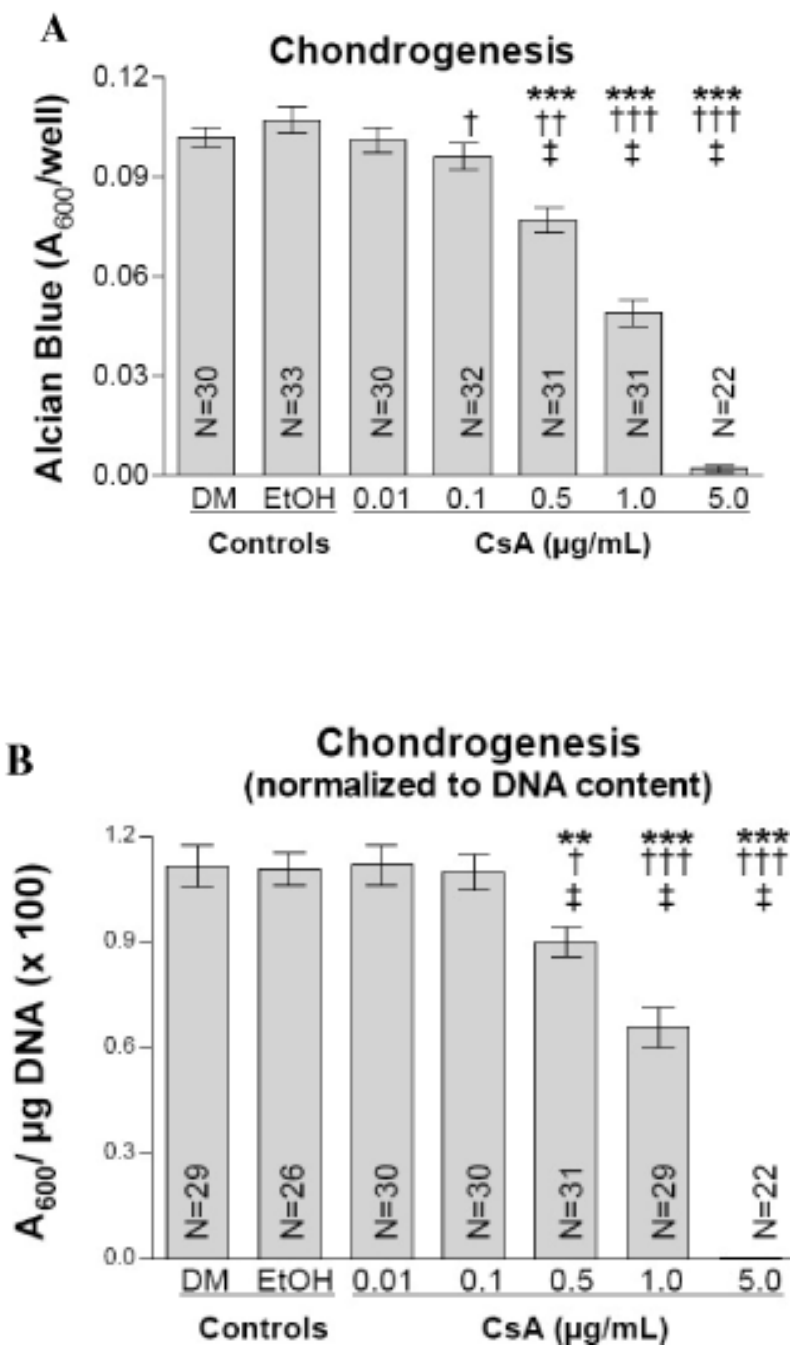

unlikely that the vehicle contributed significantly to the findings reported here.

\section{Chondrogenesis}

Alcian-blue-positive cartilage nodules formed in all cultures except the $5 \mu \mathrm{g} \mathrm{CsA} / \mathrm{ml}$ treatment group by day 4 . CsA treatment decreased the amount of cartilage formed per well over the 4-day culture period in an apparently concentration-related manner (Figure 1). The degree of nodule segregation from internodular cells and the staining intensity of the individual nodules showed an apparent, concentration-related reduction. Based on spectrophotometric analyses of the GuHCl extracts [Figure 2(A)], CsA effects at the lowest concentration $(0.01 \mu \mathrm{g} / \mathrm{ml})$ were not significant in comparison to either control. Treatment with $0.5,1$, and $5 \mu \mathrm{g} \mathrm{CsA} / \mathrm{ml}$ caused significant reductions in chondrogenesis in comparison with the DM controls $[P<0.001$; Figures 1 and $2(\mathrm{~A})]$. In comparison with vehiclecontrol values, treatment with $0.1,0.5,1$, and $5 \mu \mathrm{g} \mathrm{CsA} / \mathrm{ml}$ caused significant reductions in chondrogenesis $[P<0.05$, $<0.01,<0.001,<0.001$, respectively; Figures 1 and 2(A)]. Chondrogenesis in these three treatment groups was also significantly different from all other treatment groups $(P<0.001)$. Spearman rank correlation testing confirmed that CsA-mediated chondrogenic inhibition was concentrationdependent [Vs DM-only and vs vehicle control; $P<0.001$, $r=-1$; Figure $2(\mathrm{~B})]$.

Because cell density is an important factor during chondrogenesis in limb-bud mesenchymal cell cultures, normalizing quantitative measures of chondrogenesis to DNA content (our previous data) can be helpful in assessing the extent to which the observed effects may be attributable to alterations in cell density. The method described allows chondrogenesis measurements to be obtained for each well rather than companion cultures, providing an internal control for the effects of cell density. Values were normalized for each well by dividing the net $A_{600}$ for the extracted Alcian-blue stain by the $\mu \mathrm{g}$ DNA (previous data) and multiplying the result by 100 . This creates a separate and perhaps more reliable data set for evaluating treatment effects on chondrogenesis. These normalized values showed significant inhibition of chondrogenesis for CsA treatments at 0.5, 1.0, and $5.0 \mu \mathrm{g} /$ $\mathrm{ml}$, as compared with either the DM-only control $(P<0.005$, $P<0.001, P<0.001$, respectively) or the vehicle control $[P<0.05, P<0.001, P<0.001$, respectively; Figure 2(B)]. Spearman rank correlation testing again confirmed that CsAmediated inhibition of chondrogenesis to be concentrationdependent [Vs DM-only and vs vehicle control: $P=0.005$, $r=-0.943$; Figure 2(B)]. Effects at $5.0 \mu \mathrm{g} \mathrm{CsA} / \mathrm{ml}$, although significant, were viewed as uninterpretable because of the paucity of cells remaining at the end of the culture period.

\section{Discussion}

The effects of CsA demonstrated in the present study on in vitro chondrogenesis shows a concentration-dependent inhibition and supports the view that immunosuppressive agents affect cell differentiation in cells and tissues other than their intended lymphoid targets. ${ }^{[5,6]}$ Despite the consensus that CsA affects cell function through interactions with calcineurin, ${ }^{[4]}$ the outcome of CsA treatment at the cellular level is highly variable. Apparent inconsistencies in the reported effects likely reflect tissue- and cell-type-specific responses to CsA treatment, confirming the importance of individual studies of potential target systems.

In studies of adult and embryonic skeletal and connective tissues, CsA has been reported to both enhance and inhibit extracellular matrix (ECM) production. CsA-mediated 
enhancement of ECM production by fibroblasts has been demonstrated for renal and gingival tissues. ${ }^{[13,14]}$ Several reports provide evidence of CsA-mediated disruption of the balance between ECM synthesis and degradation in bone. In rodents, CsA treatment causes severe osteopenia in sites of high bone turnover. In vitro studies on osteoblast cell lines have shown that CsA alters ECM synthesis and degradation. It inhibits osteoblast proliferation, alkaline phosphatase activity, and cell attachment without affecting parathyroid hormone binding or cAMP levels. ${ }^{[25]}$ In another study, CsA was also shown to decrease collagen type 1 production and to increase matrix metalloproteinase activity. ${ }^{|26|}$ On the other hand, CsA inhibits chicken osteoclast differentiation and bone resorption in vitro. ${ }^{[27]}$ All these studies are in accordance with the present study, which confirms the inhibitory effects of CsA on chondrogenesis. Indeed, the CsA decreased the ECM productin and cell differentiation.

Reports of CsA's effects on cartilage and chondrogenesis are rare. A case report of skeletal malformations in an infant born to a woman on CsA therapy ${ }^{[11]}$ is suggestive of an effect on chondrogenesis but is hardly conclusive and does not address etiology. CsA inhibits mandibular condylar cartilage maturation in young rats, ${ }^{[281}$ but actually enhances chondrogenesis and osteogenesis during repair of surgically created mandibular defects in older animals receiving human demineralized bone grafts; ${ }^{\mid 29]}$ an effect suggested to reflect CsA-mediated suppression of the immune response to the xenograft.

Miniero et al. published a retrospective survey in Italy reporting that $29.2 \%$ of pregnant women that had taken immunosuppressive experienced miscarriage. ${ }^{[30]}$ Miscariage could be due to congenital defects leading to termination of pregnancy. In another study, Miniero found out that out of eight infants born from transplant recipient mother, one had congenital talipes valgus. ${ }^{[31]}$ His finding confirms the CsA effects on congenital abnormalities and skeletal malformation and it is in accordance with the present study.

CsA's ability to disrupt embryonic chondrogenesis, as indicated by effects on nodule morphology and inhibition of matrix accumulation, seems clear under the present experimental conditions and previous study, which showed the CsA effects on cell proliferation and therefore cells and ECM production were reduced under CsA therapy. ${ }^{\mid 21]}$ However, chondrogenesis is a complex process involving the spatiotemporal coordination of many cellular and molecular mechanisms. ${ }^{[17]}$ The observed disruption of cartilage histogenesis and cytodifferentiation may reflect direct effects on gene expression and/or more indirect effects on cell adhesion, cellular rearrangements, and interactions required for nodule formation, cellular metabolism, or aspects of matrix synthesis, secretion, assembly, or turnover.

An obvious starting point for studies of the mechanism underlying CsA-mediated disruption of chondrogenesis is the calcineurin signaling pathway. In mouse limb-bud micromass cultures, calcineurin overexpression has been reported to enhance chondrogenesis through interactions with the nuclear factor of activated T-cells (NFAT) isoform, NFAT4 (x, c3), and downstream effects of the activated transcription factor complex on BMP2 production. ${ }^{[32 \mid}$ The specificity of this signaling mechanism is underlined by evidence that NFAT1 (p, c2) actually inhibits chondrogenesis. ${ }^{[33]}$ Upstream activators of the calcineurin/NFAT signaling pathway, such as the Wnt family of signaling molecules ${ }^{[7]}$ are known to have important effects on chondrogenesis and cellular adhesion. ${ }^{[34]}$ Misexpression of Wnt-7a, but not Wnt-5a, strongly inhibits the chondrogenesis of primary chick limb mesenchymal cells in vitro. ${ }^{[35]}$ Additional studies of calcineurin and NFAT-isoform expression patterns, their transcriptional targets, as well as CsA's role in modulating calcineurin/NFAT-isoform association at different stages of skeletal development will improve our understanding of chondrogenesis and may provide further guidance in the use of CsA as a therapeutic agent.

\section{Conclusion}

CsA's effects on chondrogenesis in this study provide a further example of its effects on nonlymphoid tissues. CsA caused a concentration-dependent inhibition of chondrogenesis in 4-day cultures of chick limb-bud mesenchymal cells isolated from stage-23 to stage- 24 chick embryos. Its most significant inhibitory effects occurred at treatment concentrations of 0.5 and $1.0 \mu \mathrm{g} / \mathrm{ml}$, which fall within the expected circulating levels in patients receiving immunosuppressive CsA therapy. Whether this inhibition of chondrogenesis reflects an influence on cell adhesion, the cellular rearrangements necessary to form the cartilage nodules, cellular metabolism, matrix synthesis and secretion, or more direct effects on gene expression remains to be determined. Nevertheless, the findings provide new information regarding CsA's effects on chondrogenesis from embryonic mesenchyme and appropriate CsA concentrations for use in further studies. In addition, they validate a useful model system for pursuing studies of CsA's effects on these mechanisms.

\section{Acknowledgments}

This study was supported by NIH grants GM08248 and RR03036 to the Morehouse School of Medicine (MSM) and by sabbatical support to SB from Shiraz University of Medical Sciences (SUMS). The authors thank Dr. Mary Scanlon and Andrew Shaw in MSM's Image Analysis Facility for advice and assistance, and Dr. N. Zare, F. Dehbozorgian and A. Baghaei in the SUMS Statistical Consultation Center for assistance with the statistical analysis. We also thank Dr. Comnuan Nokkaew and Candace Marshall for technical assistance.

\section{References}

1. Calne R. Cyclosporine as a milestone in immunosuppression. Transplant Proc 2004;36:13-5.

2. Rizzardi GP, Harari A, Capiluppi B, Tambuzzi G, Ellefsen K, Ciuffreda D, et al. Treatment of primary HIV-1 infection with cyclosporin A coupled with highly active antiretroviral therapy. J Clin Invest 2002;109:681-8.

3. Di Padova FE. Pharmacology of cyclosporine (Sandimune). V. Pharmacological effects on immune function: In vitro studies. Pharmacol Rev 1990;41:373-405

4. Liu J, Farmer JD, Jr, Lane WS, Friedman J, Weissman I, Schreiber SL. Calcineurin is a common target of cyclophilin-cyclosporin A and FKBPFK506 complexes. Cell 1991;66:807-15.

5. Akhlaghi F, Trull AK. Distribution of cyclosporin in organ transplant recipients. Clin Pharmacokinet 2002;41:615-37.

6. Kung L, Batiuk TD, Palomo-Pinon S, Noujiam J, Helms LM, Halloran PF. Tissue distribution of calcineurin and its sensitivity to inhibition by cyclosporine. Am J Transplant 2001;1:325-33. 
7. Kuhl M. The WNT/calcium pathway: biochemical mediators, tools and future requirements. Front Biosci 2004;9:967-74.

8. Liberatoire $\mathrm{CM}$, Yutzey KE. Calcineurin signaling in avian cardiovascular development. Dev Dyn 2004;229:300-11.

9. Bar Oz B, Hackman R, Einarson T, Koren G. Pregnancy outcome after cyclosporine therapy during pregnancy:A meta-analysis. Transplantation 2001;71:1051-5.

10. Sangalli L, Bortolotti A, Passerini F, Bonati M. Placental transfer, tissue distribution and pharmacokinetics of cyclosporine in the pregnant rabbit. Drug Metab Dispos 1990;18:102-6.

11. Prevot A, Martini S, Guignard JP. In utero exposure to immunosuppressive drugs. Biol Neonate 2002;81:73-81.

12. Pujals JM, Figueras G, Puig JM, Lloveras J, Aubia J, Masramon J. Osseous malformation in baby born to woman on cyclosporin. Lancet 1989;25:667.

13. Shulz R, Yutzey KE. Calcineurin signaling and NFAT activation in cardiovascular and skeletal muscle development. Dev Biol 2004;266:1-16.

14. Wolf G, Killen PD, Neilson EG. Cyclosporin A stimulates transcription and procollagen secretion in tubulointerstitial fibroblasts and proximal tubular cells. J Am Soc Nephro 1990;1:918-22.

15. Stabellini G, Calastrini C, Mariani G, Gioia M, Caramelli E, Gangliano N, et al. Extracellular glycosaminoglycan changes in healthy and overgrown gingiva fibroblasts after cyclosporin $\mathrm{A}$ and cytokine treatments. $\mathrm{J}$ Oral Pathol Med 2004;33:346-53.

16. Paulsen DF, Chen WD, Scineaux T, Adams D. Rapid, fluorometric DNA determination for chick limb bud mesenchymal cell microcultures. In vitro Cell Dev Biol Animal 1998;34:158-62.

17. DeLise AM, Stringa E, Woodward WA, Mello MA, Tuan RS. Embryonic limb mesenchyme micromass culture as an in vitro model for chondrogenesis and cartilage maturation. Methods Mol Biol 2000;137:359-75.

18. Daniels K, Reiter R, Solursh M. Micromass cultures of limb and other mesenchyme. Methods Cell Biol 1996;51:237-47.

19. Hassell JR, Horigan EA. Chondrogenesis: A model developmental system for measuring teratogenic potential of compounds. Teratol Carcinogen Mutagen 1982;2:325-31.

20. Iozzo RV. Matrix proteoglycans: From molecular design to cellular function. Ann Rev Biochem 1998;67:609-52.
21. Bahmanpour S, Paulsen DF. Cyclosporine effects on chick limb bud mesenchyme and DNA content. Indian J Med Sci 2003;28:180-4.

22. Holt DW, Johnston A, Kahan BD, Morris RG, Oellerich M, Shaw LM. New approaches to cyclosporine monitoring raise further concerns about analytical techniques. Clin Chem 2000;46:872-4.

23. Carlson BM, Simandl BK, Stocker KM, Connelly TG, Fallon JF. A method for combined gross skeletal staining and feulgen staining of embryonic chick tissue. Stain Technol 1986;61:27-31.

24. Hoffman LM, Kulyk WM. Alcohol promotes in vitro chondrogenesis in embryonic facial mesenchyme. Int J Dev Biol 1999;43:167-74.

25. McCauley LK, Rosol TJ, Capen CC. Effects of cyclosporin A on rat osteoblasts (ROS 17/2.8 cells) in vitro. Calcif Tiss Int 1992;51:291-7.

26. Fornoni A, Cornacchia F, Howard GA, Roos BA, Striker GE, Striker LJ. Cyclosporin $A$ affects extracellular matrix synthesis and degradation by mouse MC3T3-E1 osteoblasts in vitro. Nephrol Dial Tranplant 2001;16:5005.

27. Chowdhury MH, Shen V, Dempster DW. Effects of cyclosporine A on chicken osteoclasts in vitro. Calcif Tiss Int 1991;49:275-9.

28. Nieh S, Fu E, Hsieh YD, Wikesjo UM, Shen EC. Effects of cyclosporine A on the mandibular condylar cartilage in rats. Arch Oral Biol 1999;44:693700.

29. Fu E, Tseng YC, Shen EC, Hsieh YD, Chiang CY. Effects of low-dose cyclosporin on osteogenesis of human demineralized bone grafts in surgically created mandibular defects in rats. J. Peridontol 2003;74:1136-42.

30. Miniero R, Tardivo I, Curtoni ES, Bresadola F, Calconi G, Cavallari A. Outcome of pregnancy after organ transplantation:a retrospective survey in Italy. Transpl Int 2005;17:724.

31. Miniero R, Tardivo I, Centofanti P, Goggi C, Mammana C, Parisi F. Pregnancy in heart transplant recipients. J Heart Lung Transplant 2004;23:898.

32. Tomita M, Reinhold MI, Molkentin JD, Naski MC. Calcineurin and NFAT4 induce chondrogenesis. J Biol Chem 2002;277:42,214-8.

33. Tufan AC, Daumer KM, Tuan RS. Frizzled-7 and limb mesenchymal chondrogenesis: effect of misexpression and involvement of $\mathrm{N}$-cadherin. Dev Dyn 2002;223:241-53.

34. Daumer KM, Tufan AC, Tuan RS. Long-term in vitro analysis of limb cartilage development: Involvement of Wnt signaling. Cell Biochem 2004;93:526-41.

\title{
PP SURYA KUMAR PRIZE
}

INDIAN PHARMACOLOGICAL SOCIETY

\begin{abstract}
PP Surya Kumari prize is awarded by IPS every year for the best research paper published in any journal on "diabetes mellitus, other endocrinal and metabolic disorders" in the last five years. The prize is open to Indian scientists working in Indian laboratories. The award is presented to the winner at the annual conference of IPS.
\end{abstract}

Those who wish to compete for the prize for the year 2006 may submit five reprints/copies of the paper (published in 2001-2005) to the Chief Editor, Indian Journal of Pharmacology at the following address on or before 31st March 2006.

E-mail : ijp@jipmer.edu

Prof. R. Raveendran

Phone: 0413-2271969

Convener, PP Surya Kumari Prize,

Fax: 0413-2272067

The Chief Editor-IJP,

Department of Pharmacology,

JIPMER, Pondicherry - 605 006. India 